\title{
A escola na comunidade, a comunidade na escola
}

Vera Santana

O relato descreve o Projeto “Conexão Felipe Camarão”, que acontece na comunidade Felipe Camarão, em Natal - Rio Grande do Norte. A iniciativa é realizada pela Associação Companhia Terramar, organização não-governamental que se ocupa do desenvolvimento integral de crianças e jovens e da difusão, preservação e valorização da cultura da comunidade, em especial dos patrimônios imateriais. A experiência inclui oficinas de arte e cultura para crianças e jovens, montagem e apresentação de espetáculos, discussões sobre temas de interesse público, artesanato e parceria com escolas e espaços culturais. Esse último aspecto - a parceria com escolas e espaços culturais tem papel fundamental nas ações do projeto, já que a educação é encarada como aliada para promover a preservação da cultura local. Trata-se, pois, de um relato de experiência sobre as ações de um projeto que relaciona de forma bemsucedida educação e cultura, descrevendo as interações entre a comunidade e as escolas que a compõem.

Palavras-chave: Felipe Camarão (RN); Associação Companhia Terramar; preservação do patrimônio cultural; 


\section{School in community, community}

\section{in school}

Vera Santana

The report describes the Project "Conexão Felipe Camarão", that takes place in community Felipe Camarão, in Natal - Rio Grande do Norte. The initiative is carried out by Associação Companhia Terramar, a non-governmental organization that deals with the integral development of children and youngsters and the dissemination, preservation and valuation of the culture of the community, in particular of the immaterial assets. The experience includes art and culture workshops for children and young people, mounting and showing spectacles, discussion on subjects of public interest, handcraft and partnership with schools and cultural spaces. This last aspect - the partnership with schools and cultural spaces - has a fundamental role in the actions of the project, since education is faced as an ally to promote the preservation of local culture. This is, therefore, an experience report on the actions of a project that successfully relates education and culture, describing the interactions between the community and the schools that comprise it.

key words: Felipe Camarão (RN); Associação Companhia Terramar; preservation of cultural assets; 


\title{
A escola na comunidade, a comunidade na escola.
}

\author{
Vera Santana
}

\section{Resgatar a memória cultural e desenvolver} crianças e jovens

\section{OProjeto Conexão Felipe Camarãoacontecena comunidade} de Felipe Camarão, em Natal (RN), um dos berços da cultura potiguar, marcada pela contradição entre riqueza cultural e pobreza econômica. É realizado pela Associação Companhia Terramar - organização não governamental que objetiva contribuir com o desenvolvimento integral de crianças e jovens da comunidade, por meio da preservação, valorização e difusão da cultura local. Suas ações estão fundamentadas nos patrimônios imateriais locais: o Auto do Boi de Reis do mestre Manoel Marinheiro (in memoriam), o teatro de bonecos João Redondo do mestre Chico de Daniel (in memoriam), a musicalidade do mestre Cícero da Rabeca e a capoeira do mestre Marcos.

O trabalho surgiu com o projeto Canta Meu Boi, patrocinado pela Petrobras - Música, realizado entre 2003 e 2004, que promoveu o registro fonográfico do Auto do Boi de Reis do mestre Manoel Marinheiro e garantiu, quando ele ainda vivia, o reconhecimento, pelo Ministério da Cultura, de seu empenho e atuação como Patrimônio Cultural Brasileiro.

A experiência resultou no desdobramento do trabaIho, com a aprovação na Lei Federal de Incentivo à Cultura do Conexão Felipe Camarão, a partir de 2005. É um projeto socioeducacional e cultural, dedicando-se à preservação da memória cultural do bairro e ao desenvolvimento integral de crianças e jovens da comunidade de Felipe Camarão.

\footnotetext{
* Vera Santana é historiadora, produtora cultural e coordenadora do Ponto de Cultura Conexão Filipe Camarão
}

Atualmente, o Conexão Felipe Camarão é Ponto de Cultura do Programa Cultura Viva do Ministério da Cultura e realiza várias ações, como oficinas de arte e cultura, atividades integradas às cinco escolas parceiras, montagem e apresentação de espetáculos culturais, discussões sobre temas de interesse público, além de agregar programas como o Ação Griô Nacional ${ }^{1}$ - Programa Cultura Viva do Ministério da Cultura e o GESAC - Ministério das Comunicações.

Implementou, em 2009, o Núcleo de Moda, Estilos e Costumes, Figurinos e Adereços - um polo artesanal de artigos, moda e adereços, com base na iconografia e cultura locais. Integra diretamente 400 crianças e jovens da comunidade e seus familiares, além de estender suas ações para as escolas parceiras e espaços sociais, como a Casa de Cultura Mestre Manoel Marinheiro e o Largo da Cruz da Cabocla - terreiro do mestre Manoel Marinheiro.

Atuando junto a cinco escolas públicas do bairro, parceiras, com as quais desenvolve atividades regulares que valorizam a cultura local, o Projeto Conexão Felipe Camarão discute educação e cultura por meio de círculos de debates entre educadores, mestres de tradição oral e as crianças e jovens. Acreditando na importância de aliar a educação à cultura, na perspectiva da preservação da cultura local, realiza uma busca coletiva de alternativas pedagógicas e ações educativas que permitam o diálogo entre o conteúdo escolar e o cotidiano local.

Considerar no processo educativo a riqueza cultural que faz parte do cotidiano das crianças e jovens é um passo fundamental para que eles compreendam a realidade em que vivem e dialoguem com ela, entendendo-se como sujeitos sociais ativos na construção coletiva dos espaços e como sujeitos históricos. Essas são as bases fundamentais dos pressupostos político-filosófi- 


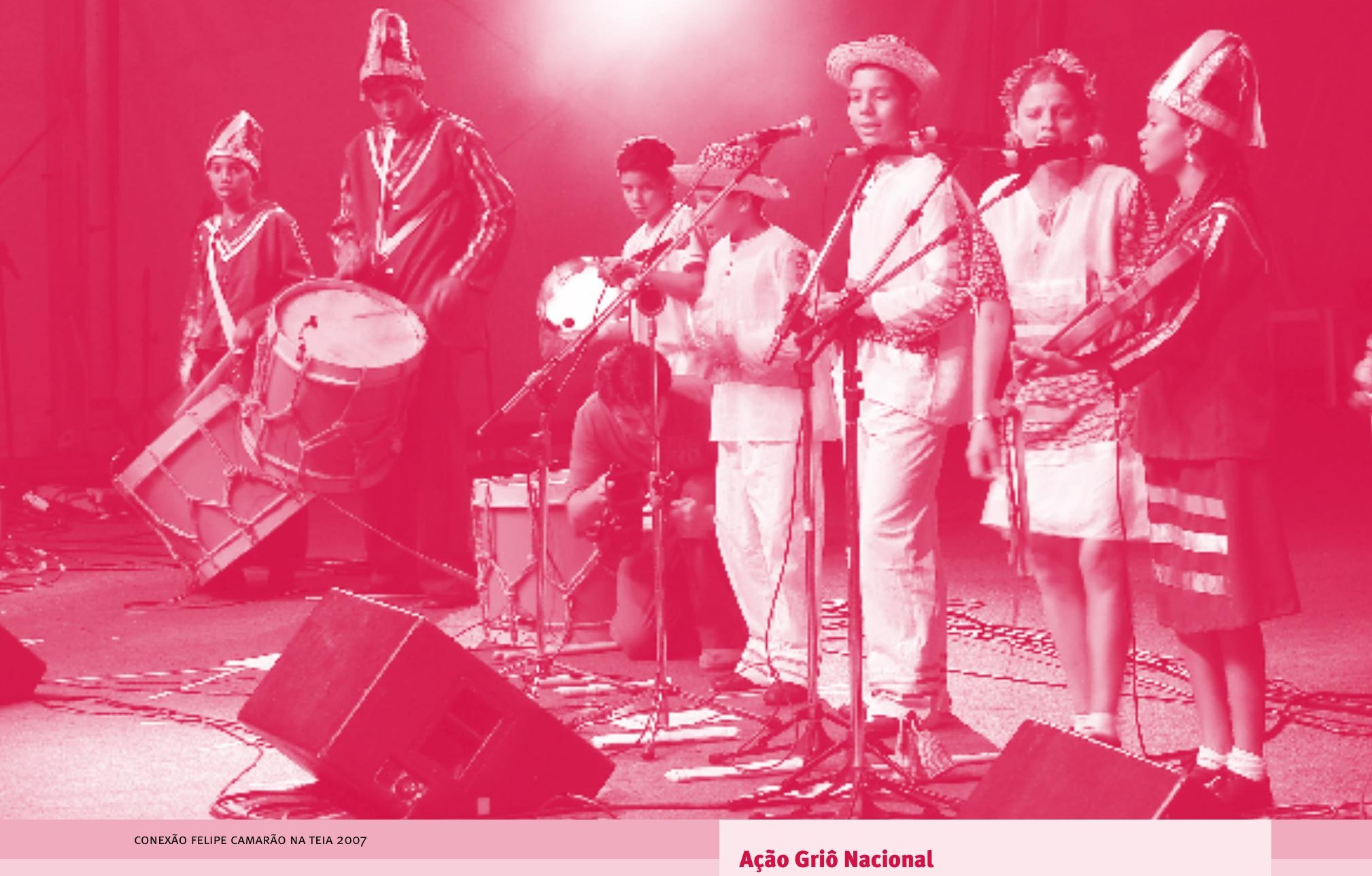

cos do educador Paulo Freire, que, junto com outros brasileiros, como Darcy Ribeiro, Anísio Teixeira, Milton Santos e Amir Haddad, fundamentam a linha de ação política do projeto e dão sustentação aos ideais de uma educação transformadora e libertadora.

É nesse sentido que o Projeto Conexão alia educação à cultura, sem a qual não é possível estabelecer o diálogo entre o que se aprende e o que se vive, entre o conteúdo escolar e o cotidiano. A metodologia empregada faz uso desses aspectos, através dos círculos de cultura, dos momentos de debate e uso da palavra, e considera todos os envolvidos como sujeitos da ação, educadores e mestres, alunos e aprendizes. 0 processo de construção coletiva das ações e a reflexão contínua sobre o que se faz são vivenciados semanalmente, analisando-se avanços e dificuldades.

Repensar sistematicamente o espaço da escola faz parte da metodologia de trabalho, provocando a reflexão sobre os processos de aprendizagem. Ao mesmo tempo, traz para dentro do espaço escolar, para a sala de aula, a cultura que está lá fora, e leva para fora o conteúdo que está dentro da escola.

\section{Em 2006, a Ação Griô foi lançada no Encontro}

Sul-Americano de Culturas Populares e na TEIA, além de outros encontros nacionais e regionais, com a distribuição do livro Pedagogia Griô: a reinvenção da roda da vida; a apresentação e distribuição do filme Sou Negro; e a divulgação da página www.graosdeluzegrio.org.br, com a experiência do Grãos de Luz e Griô de Lençóis, na Bahia, como referência para todos os Pontos de Cultura do Brasil.

O Grãos de Luz e Griô e o MinC elaboraram e publicaram o Edital Ação Griô $\mathrm{n}$ 우 1, em 15 de setembro de 2006, aberto aos Pontos de Cultura do Programa Cultura Viva da Secretaria de Programas e Projetos Culturais do MinC (atual Secretaria da Cidadania Cultural).

Sua missão é criar e instituir uma política nacional de transmissão dos saberes e fazeres de tradição oral em diálogo com a educação formal, para o fortalecimento da identidade e ancestralidade do povo brasileiro, por meio do reconhecimento do lugar político, econômico e sociocultural dos griôs, das griôs, mestres e mestras de tradição oral do Brasil. 
As experiências das Rodas de Prosa - círculos de debates que ocorrem periodicamente e abordam problemas e temas de interesse coletivo - são um exemplo de como o processo de aprendizagem é mais eficiente quando se alargam suas possibilidades, tendo como ponto de partida os problemas, as situações e os sujeitos reais.

Nessas ocasiões, reúnem-se educadores, comunidade, familiares, escolas, instituições, mestres, crianças e jovens em torno de temas que fazem parte do cotidiano de cada um. Os temas se transformam em objeto de conhecimento e de reflexão, ampliando-se o espaço de aprendizagem e tornando todos capazes de aprender e de ensinar, pelo uso da palavra, do diálogo de visões de mundo, posições, saberes e gerações.

A linha de ação política que orienta o Conexão Felipe Camarão parte do pressuposto de que a cultura é um elemento imprescindível para a compreensão do indivíduo e da realidade que o cerca. Sem memória cultural não há identidade, nem pertencimento, nem história. Suas ações educativas, portanto, fundamentam-se na valorização, preservação e difusão da cultura de tradição oral da comunidade, utilizando-se de estratégias que vão desde a socialização dos saberes da tradição até o diálogo com as tecnologias e culturas digitais - novos saberes, que auxiliam no processo de resgate e preservação da memória cultural.

A discussão coletiva da cultura como elemento de compreensão e de transformação social é ponto de partida para abordar temas como memória, identidade e cidadania. Nessas oportunidades, trata-se a cultura como muito mais do que representação coletiva do imaginário social, mais do que forma de viver e história social de um povo; ela se configura como constituição do que somos, de como nos formamos e como poderemos ser.

O Conexão trata desses aspectos a partir da história da formação do povo brasileiro e suas matrizes culturais, através dos quais é possível compreender e refletir sobre a realidade como processo social. Ou seja, é possível pensá-la como uma construção social, feita por sujeitos ativos e históricos, o que constitui a própria noção de cidadania.

\section{Mais autonomia e personalidade}

\section{Conexão Felipe Camarão tem, ao longo dos anos,} contribuído para o desenvolvimento integral de crianças e jovens da comunidade, a partir de ações de preservação, valorização e difusão da cultura local, entendendo a sua prática como ação educativa e social.
A atuação que vem realizando evidencia que há um crescimento coletivo e individual das crianças e jovens, gradativamente, perceptível de várias formas:

- aprimoramento de suas habilidades;

- aumento das capacidades de dialogar e de interagir;

- desenvolvimento da aprendizagem (musical, artística, de liderança etc.);

- melhor desempenho nas atividades escolares ou não;

- aprimoramento de competências particulares e coletivas;

- ampliação da capacidade de discutir, de se expressar, de questionar.

Para além da qualidade musical - muitos se revelam com habilidades na música, composição, desenho, interpretação, entre outros aspectos -, algumas consequências se destacam: ao se apoderarem não só de sua própria cultura, mas de todas as possibilidades que essa cultura lhes dá, crianças e jovens ficam mais aptos a dizerem o que pensam, a terem autonomia e personalidade.

Crescimento e desenvolvimento das crianças exigem uma equipe muito articulada e preparada. Por isso o Conexão Felipe Camarão desenvolve formação continuada com toda a equipe. Semanalmente, são realizados os círculos de cultura, momento de planejamento coletivo e avaliação constante do trabalho, reunindo educadores, mestres de tradição oral, coordenadores e crianças e jovens integrantes das ações.

Em alguns momentos, os círculos contam com a presença de educadores das escolas parceiras para o planejamento e avaliação das atividades integradas projeto-escola. Participam também outros sujeitos como representantes da comunidade, dos pais, da unidade básica de saúde, para a decisão de ações que envolvem a comunidade em geral ou para tratar de algum problema que exija o diálogo entre esses sujeitos.

Os círculos de cultura são uma metodologia em que todos os participantes dialogam a partir de suas experiências, possibilitando que o debate se realize em todas as instâncias do projeto.

A formação também se dá periodicamente em momentos específicos, chamados de Roda de Prosa: é uma ação realizada diretamente com as escolas parceiras, em que são discutidos temas de interesse coletivo. A Roda de Prosa conta com a presença dos sujeitos sociais já citados e a participação de órgãos públicos e instituições que têm responsabilidade ou domínio sobre o tema em discussão. 
Geralmente acontecem três Rodas de Prosa por ano, viabilizando uma formação continuada a cada quatro meses e abordando temas dos mais variados. A metodologia inclui a discussão prévia do tema nas escolas e a preparação de crianças e jovens, educadores e mestres para a Roda, promovendo o processo de aprendizagem e socialização do tema. Já foram abordados assuntos como diretos humanos, meio ambiente e sustentabilidade, cultura brasileira e musicalidade, educação e cidadania.

\section{Diálogo de saberes}

\section{O Conexão Felipe Camarão atua na perspectiva de que} as ações são desenvolvidas a partir do diálogo de saberes entre educadores, mestres de tradição oral, crianças, jovens e aprendizes. Há vários saberes que convivem nas ações, vivenciados no cotidiano do projeto e inseridos nas relações que se estabelecem e que se sustentam pela rede social.

O papel dos educadores e dos mestres de conduzir os diálogos de saberes se concretiza na compreensão do processo de aprendizagem da tradição, que passa dos mais velhos para os mais novos, considerando que os diálogos com as gerações mais novas trazem desafios aos novos saberes e suas ferramentas. Esses aspectos são observados no cotidiano do projeto, por envolver educadores com formação específica, mestres de tradição oral, que acumulam seus saberes pela história de vida. 0 programa Ação Griô Nacional intensifica a importância desses mestres no contexto educacional e no diálogo com a escola, e também agrega crianças e jovens, influenciados por todas as formas de cultura e tecnologias digitais e saberes novos, diferentes da tradição.

O diálogo que o Conexão Felipe Camarão estabelece com as escolas reflete também sobre o papel do professor que está na escola com um conteúdo a ser trabalhado e que precisa abrir-se para o universo que está fora da sala de aula e do contexto da escola, dialogando com saberes que são de outras instâncias, mas que servem de ponte para o conhecimento formal e a aprendizagem das crianças e jovens.

A mediação do processo de aprendizagem deve considerar esses aspectos e viabilizar que haja um equilíbrio entre passado e presente, conteúdo e cotidiano, vida e aprendizado. É nesse sentido que o Conexão Felipe Camarão tem realizado um trabalho que busca dialogar saberes, relacionando educação e cultura.
Nota

1. É patrocinado pelo Programa Petrobras Cultural e tem o copatrocínio da Votorantim.

Fontes

http://www.carolinaniemeyer.com/Em_andamento/index. php?pg=pagina\&areasite_id=000017; acesso: 23 de fevereiro de 2010; 16:50.

http: / / www.carolinaniemeyer.com/Em_andamento/index. php?pg=pagina\&areasite_id=000018; acesso: 23 defevereiro de 2010, 16:55.

A mediação do processo de aprendizagem deve considerar esses aspectos e viabilizar que haja um equilíbrio entre passado e presente, conteúdo e cotidiano, vida e aprendizado. É nesse sentido que o Conexão Felipe Camarão tem realizado um trabalho que busca dialogar saberes, relacionando educação e cultura. 